\title{
POTENCIAL HIDRÁULICO EM BACIAS HIDROGRÁFICAS I: IDENTIFICAÇÃO DE QUEDAS DE ÁGUA PARA GERAÇÃO DE ENERGIA ELÉTRICA ${ }^{1}$
}

Reynaldo Furtado Faria Filho², João Batista Lopes Silva ${ }^{3}$, Paulo Afonso Ferreira ${ }^{4}$, Humberto Paulo Euclydes ${ }^{5}$, Delly

\author{
Oliveira Filho ${ }^{6}$
}

\section{RESUMO}

Neste trabalho foram utilizados os Sistemas de Informações Geográficas, a fim de desenvolver uma metodologia para identificar, em sub-bacias, seções com potencial para geração de energia hidrelétrica. $\mathrm{O}$ estudo foi desenvolvido na sub-bacia do rio Turvo Sujo, bacia do rio Doce. Para obter o modelo digital de elevação hidrologicamente consistente (MDEHC), utilizaram-se dados de altimetria e hidrografia do IBGE (Instituto Brasileiro de Geografia e Estatística), pontos cotados por levantamento topográfico e dados digitais de altimetria SRTM (Shuttle Radar Topography Mission). Com esses dados, foram gerados oito MDEHC's, com duas resoluções espaciais de células, com 5 e 10 m. Os resultados foram satisfatórios para os MDEHC's obtidos com os pontos cotados e os dados do IBGE, para ambas as resoluções. Utilizando os dados do IBGE e o SRTM, os MDEHC's obtidos para ambas as resoluções, não apresentaram resultados satisfatórios.

Palavras-chave: MDE, minicentrais hidrelétricas, Sistemas de Informações Geográficos.

\section{ABSTRACT \\ HYDRAULIC POTENTIAL IN HYDROGRAPHIC BASINS I: IDENTIFICATION OF WATERFALLS TO GENERATE HYDROELECTRIC ENERGY}

The Geographical Information Systems were used in this study, in order to develop a methodology for the identification, in sub-basin, the potential to generate hydroelectric energy. The study was carried out in the sub-basin of Turvo river, that is located of the Doce river basin. To obtaining the hydrologically consistent digital model (MDEHC), the following were used: altimetry and hydrography data obtained from maps in site of the IBGE (Instituto Brasileiro de Geografia e Estatística); quoted points obtained by topographical survey; and digital altimetry data SRTM (Shuttle Radar Topography Mission). Eight MDEHC's were generated with two cells resolutions, 5 and $10 \mathrm{~m}$. The results was satisfactory for MDEHC's using the input data from points quoted plus IBGE, for both resolutions, while the MDEHC's by using IBGE plus SRTM data the results was not satisfactory, for both resolutions.

Keywords: DEM, hydroelectric minicentrals, Geographical Information Systems.

\section{Recebido para publicação em 13/08/2009. Aprovado em 11/05/2010}

1- Texto extraído da dissertação de mestrado do primeiro autor.

2- Engenheiro Agrimensor, Mestre em Engenharia Agrícola, avreynaldo@yahoo.com.br.

3- Engenheiro Agrícola, Mestre em Engenharia Agrícola, silvajbl@yahoo.com.br.

4- Agrônomo, Ph. D. em Engenharia de Água e Solo, pafonso@ufv.br.

5- Engenheiro Agrícola, Mestre em Engenharia Agrícola, hpeuclyd@ufv.br.

6- Engenheiro Eletricista, Ph. D. em Engenharia Elétrica, delly@ufv.br. 


\section{INTRODUÇÃO}

Analisando-se o período de 1970 a 2000, verifica-se que o consumo de energia elétrica, no Brasil, teve crescimento superior à taxa mundial, quando o número total de consumidores passou de 8,1 milhões, em 1970, para 47,3 milhões, em 2000 (SUGAI, 2003). O número de ligações elétricas residenciais subiu de 6,8 milhões para 40,5 milhões, correspondendo a um crescimento médio anual de $6,1 \%$, o que representa um acréscimo de $45 \%$ em domicílios atendidos, registrados em 1970, para cerca de $96 \%$, em 2000 (CCPE, 2002).

Assim, o crescente desequilíbrio entre a oferta e a demanda por energia elétrica, aliado aos baixos investimentos em ampliação das redes de transmissão de alta tensão e em novas concessionárias do setor, culminou na crise energética de 2001 (PREFEITO; MAUAD, 2004). Diante dessa crise, o Ministério de Minas e Energia (MME) assumiu atuação permanente, no sentido de garantir condições para que a iniciativa privada implementasse novas unidades geradoras, de forma rápida e eficiente, ressurgindo, no cenário nacional, as micro e pequenas centrais hidrelétricas.

Essa nova visão do setor elétrico nacional tem levado a mudanças institucionais e reguladoras, como a remoção de barreiras à entrada de novos agentes no setor da energia elétrica, incentivando pequenos empreendedores (ANEEL, 2006). Objetiva-se, com estes empreendimentos de menor porte, atender a áreas periféricas ao sistema de transmissão e àquelas decorrentes da expansão agrícola (NEVES et al., 2004).

Estudos recentes sinalizam no sentido de implementar a geração de energia elétrica descentralizada, destacando-se o papel das minicentrais hidrelétricas (MCH's) e o uso de fontes renováveis de energia, dentro do contexto de preservação e gestão ambiental (CARVALHO et al., 2004). Outro ponto, a favor dessa nova visão, é o benefício às famílias de baixa renda, sem acesso à energia, que se concentram em áreas com baixo índice de desenvolvimento humano (IDH). Cerca de $90 \%$ dessas famílias têm renda inferior a três salários-mínimos, sendo que $80 \%$ encontram-se no meio rural (MME, 2006).

Mauad et al. (2003) e Neves et al. (2004) citam como principais vantagens das MCH's, em relação aos grandes empreendimentos: (1) menor impacto ambiental e social, pois, grande parte das MCH's utilizam captação a fio de água; (2) instalação próxima ao local de consumo, evitando linhas de transmissão de grandes extensões; (3) em eventualidades de queda do sistema elétrico, as MCH's têm capacidade para atender, isoladamente, aos centros de consumo; (4) possibilidade de geração somente no horário de maior demanda do sistema elétrico, otimizando a curva de carga do sistema; e (5) menor tempo para construção e desenvolvimento em regiões remotas do país.

Como desvantagens das MCH's, Mauad et al. (2003) destacam: (1) geralmente, as microbacias onde são instaladas não possuem regularização da vazão, estando sujeitas ao regime hidrológico do rio; e (2) a continuidade de operação depende das características tecnológicas da instalação, o que implica maior demanda de sofisticação do sistema, elevando-se os respectivos custos.

Para a implantação dessas minicentrais hidrelétricas são necessários dados fisiográficos das possíveis localidades de construção do empreendimento. Neste quesito, os Sistemas de Informações Geográficas (SIG) possibilitam a obtenção rápida e acurada de parâmetros fisiográficos mais complexos, como a declividade, comprimento do curso de água principal, densidade de drenagem, entre outros.

Scartazzini (1993) utilizou um SIG para determinação automática de quedas de água, ao longo dos cursos de água de uma bacia hidrográfica e áreas de drenagem a montante delas, manipulando grande volume de dados envolvidos nos estudos hidráulicos. Segundo Das e Paul (2006), a utilização de SIG para identificar locais com potencial para geração de energia hidrelétrica em pequenas centrais hidrelétricas pode reduzir, consideravelmente, o custo, em comparação com os métodos tradicionais, fato comprovado ao identificarem locais que teriam potencial para geração de energia hidrelétrica, em Darjeeling, West Bengal, na Índia.

Dentro deste contexto, objetivou-se, neste trabalho, desenvolver uma metodologia por meio de SIG, a fim de determinar alturas de quedas de água com potência para gerar valores acima de $10 \mathrm{~kW}$, e comparar os resultados obtidos por meio desta metodologia com aqueles obtidos em campo, mediante levantamento topográfico. 
MATERIAL E MÉTODOS

Para o desenvolvimento desta metodologia, utilizou-se o software de SIG ArcGIS versão 9.0 e a sub-bacia do rio Turvo Sujo, como área de estudo (Figura 1). A sub-bacia está situada entre os paralelos $20^{\circ} 39^{\prime} \mathrm{S}$ e $20^{\circ} 53^{\prime} \mathrm{S}$ e meridianos $42^{\circ} 42^{\prime}$ $\mathrm{O}$ e $42^{\circ} 58^{\prime} \mathrm{O}$. O rio Turvo Sujo é afluente do rio Turvo Limpo, localizado nas cabeceiras do rio Doce na Zona da Mata Mineira. Sua área de drenagem é de aproximadamente $402 \mathrm{~km}^{2}$ e seu principal afluente é o ribeirão São Bartolomeu, que corta a cidade de Viçosa-MG, sendo a principal fonte de abastecimento de água para a população da cidade.

Para obter e testar diferentes modelos digitais de elevação (MDE), foram utilizados os seguintes dados: curvas de nível equidistantes de $20 \mathrm{~m}$ e hidrografia, obtidas de cartas topográficas na escala 1:50.000, do Instituto Brasileiro de Geografia e Estatística, IBGE (2006); hidrografia obtida de cartas topográficas na escala de 1:250.000 do IBGE; dados digitais de altimetria, com resolução de $90 \mathrm{~m}$, importados da base de dados Shuttle Radar Topography Mission (SRTM) versão 2.

Em visita prévia ao campo, confirmou-se a existência de uma queda de água com potencial para a geração de energia elétrica na sub-bacia do rio Turvo Sujo. Visando a melhorar a exatidão do MDE gerado e posterior comparação dos resultados, foi realizado um levantamento topográfico a montante e a jusante do referido trecho. Posteriormente, realizou-se a incorporação dos pontos cotados, obtidos a partir do levantamento, aos dados de altimetria do IBGE, obtendo-se maior detalhamento do trecho identificado.

$\mathrm{Na}$ determinação do tamanho de célula adequado à geração dos MDE's, utilizou-se a metodologia apresentada por Hutchinson (2007). Esta propõe a geração de MDE's com diferentes tamanhos de célula e a determinação da raiz quadrada média $(R M S)$ de suas respectivas declividades (Equação 1), plotando-as em gráficos. O tamanho de célula ideal é identificado no gráfico, quando a curva do tamanho de célula pelo $R M S$ torna-se assintótica. Neste estudo, geraram-se 12 modelos digitais de elevação com os seguintes tamanhos de células: 5 ; 7,$5 ; 10 ; 12,5 ; 15 ; 20 ; 25 ; 30 ; 50 ; 70 ; 90$ e 100 m. A curva estabilizou-se com tamanhos de células de 5 , 7,5 e $10 \mathrm{~m}$, sendo utilizadas neste trabalho as células com resoluções de 5 e $10 \mathrm{~m}$.

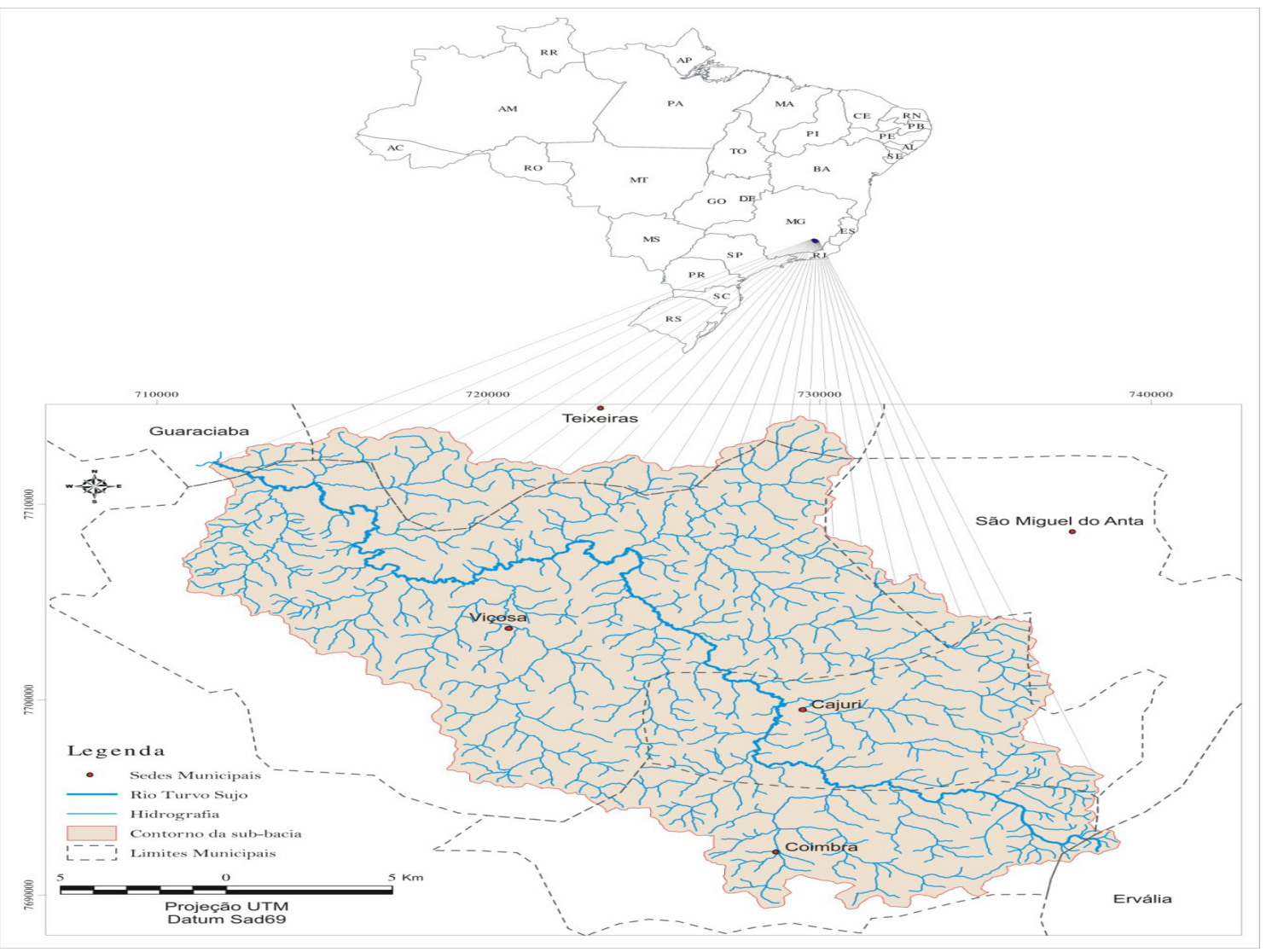

Figura 1. Localização da sub-bacia do rio Turvo Sujo, município de Viçosa - MG. 


$$
R M S=\sqrt{\frac{1}{n} \sum s^{2}}
$$

em que,

$R M S=$ raiz quadrada média da declividade (graus);

$n=$ número total de células; e

$s=$ declividade (graus).

Para identificar os locais potenciais para geração de energia hidrelétrica, foram gerados os MDE's a partir das combinações das duas resoluções espaciais (5 e $10 \mathrm{~m}$ ) e dos dados fisiográficos, resultando em oito combinações, conforme apresentado a seguir.

1 - Curvas de nível equidistantes de $20 \mathrm{~m}$, hidrografia na escala de 1:50.000 e resolução espacial de 5 m (C20M5);

2 - Curvas de nível equidistantes de $20 \mathrm{~m}$, hidrografia na escala de 1:50.000 e resolução espacial de $10 \mathrm{~m}$ (C20M10);

3 - SRTM convertido em uma malha de pontos equidistantes de $90 \mathrm{~m}$, hidrografia na escala de 1:50.000 e resolução espacial de 5 m (SRTMH50-M5);

4 - SRTM convertido em uma malha de pontos equidistantes de $90 \mathrm{~m}$, hidrografia na escala de 1:50.000 e resolução espacial de $10 \mathrm{~m}$ (SRTMH50-M10);

5 - SRTM convertido em uma malha de pontos equidistantes $90 \mathrm{~m}$, hidrografia na escala de 1:250.000 e resolução espacial de 5 m (SRTM-H250-M5);

6 - SRTM convertido em uma malha de pontos equidistantes $90 \mathrm{~m}$, hidrografia na escala de 1:250.000 e resolução espacial de $10 \mathrm{~m}$ (SRTMH250-M10);

7 - Pontos cotados, obtidos ao longo do levantamento topográfico e curvas de nível do IBGE no restante da sub-bacia, hidrografia na escala de 1:50.000 e resolução espacial de 5 m (PTCM5) e

8 - Pontos cotados, obtidos ao longo do levantamento topográfico e curvas de nível do IBGE no restante da sub-bacia, hidrografia na escala de 1:50.000 e resolução espacial de 10 m (PTCM10).

Posteriormente, realizou-se o pós-processamento dos MDE's gerados, empregando-se a metodologia descrita por Ribeiro et al. (2002), que objetiva, em suma, à obtenção dos Modelos Digitais de Elevação Hidrologicamente Consistentes (MDEHC). Por fim, verificou-se a qualidade dos MDEHC's, por comparação visual entre a drenagem numérica, gerada a partir do MDEHC, e a hidrografia mapeada.
O grau de coincidência entre estas atuou como indicador de qualidade dos MDEHC's gerados.

Conforme Eletrobrás (1985), a potência de uma queda de água para instalação de uma minicentral hidrelétrica $(\mathrm{MCH})$, considerando-se um fator médio de rendimento da turbina e do gerador, além das perdas de carga por atrito no sistema de adução, pode ser calculada por:

$P=7,5 Q H$

em que,

$P=$ potência teórica $(\mathrm{kW})$;

$Q=$ vazão $\left(\mathrm{m}^{3} \mathrm{~s}^{-1}\right)$; e

$H=$ altura de queda de água (m).

A vazão $(Q)$ utilizada, recomendada por Eletrobrás (1985), é a vazão média diária com permanência de $95 \%$ $\left(Q_{95}\right)$. Em vista de não existirem estações fluviométricas, na sub-bacia de estudo, para se obter a $Q_{95}$, utilizou-se a regionalização hidrológica existente no Atlas Digital das Águas de Minas (ATLAS, 2005). Para a sub-bacia em estudo, a $Q_{95}$ pode ser determinada por:

$Q_{95}=0,0050 A^{1,0194}$

em que,

$Q_{95}=$ vazão média diária com permanência de $95 \%$ $\left(\mathrm{m}^{3} \mathrm{~s}^{-1}\right)$; e

$A=$ área de drenagem a montante da seção fluvial $\left(\mathrm{km}^{2}\right)$.

As alturas de queda de água $(H)$ e as áreas de drenagem $(A)$, ao longo da hidrografia da sub-bacia do rio Turvo Sujo, foram obtidas para cada um dos MDEHC's gerados.

Com os valores de potência calculados para cada ponto, foi realizada uma nova seleção, determinando-se os pontos com potência maior que $10 \mathrm{~kW}$. Assim, como resultado de todos os procedimentos, obteve-se uma tabela com os valores das coordenadas, $H, A$ e $P$ de cada ponto, identificado ao longo da rede hidrográfica da bacia, com potência mínima de $10 \mathrm{~kW}$ e altura de queda de água superior a $2 \mathrm{~m}$.

Os temas de hidrografia e contorno da subbacia do rio Turvo Sujo e a tabela, contendo os pontos selecionados, deram origem ao mapa final, possibilitando uma análise visual dos resultados. 


\section{RESULTADOS E DISCUSSÃO}

De posse dos resultados das simulações realizadas com os dados originais do IBGE e do SRTM, fizeram-se visitas a campo, nos locais identificados pelas simulações como potenciais para a geração de energia hidrelétrica. Em grande parte dos locais indicados, não foi constatada a existência de quedas de água superiores a $2 \mathrm{~m}$ ou capazes de gerar, pelo menos, $10 \mathrm{~kW}$ de potência. A seguir, são descritas as características principais dos resultados, obtidos para cada simulação, quando se utilizaram os dados originais.

Na simulação C20M5, foi encontrada somente uma queda de água superior a $2 \mathrm{~m}$ e capaz de gerar potência maior que $10 \mathrm{~kW}$, a qual não foi confirmada em campo. O local indicado nessa simulação não foi identificado nas outras simulações. No entanto, a simulação C20M10 indicou dois locais potenciais para a geração de energia hidrelétrica, que também diferiram da situação de campo.

Como resultado da simulação SRTM-H50-M5, foram apresentados quatro locais potenciais para geração de energia hidrelétrica, que não foram confirmados em campo. A simulação SRTMH50-M10, entretanto, indicou cinco locais potenciais, dos quais somente um é verdadeiro, o mesmo identificado em visita prévia a campo. $\mathrm{Na}$ Figura 2, apresenta-se o mapa resultante dessa simulação, com localização e detalhamento das células dos locais com quedas de água e potência superiores a $2 \mathrm{~m}$ e $10 \mathrm{~kW}$, respectivamente. É ainda apresentada a localização da queda de água levantada em campo, possibilitando sua comparação visual com os resultados determinados com a metodologia.

As simulações SRTM-H250-M5 e SRTMH250-M10 apresentaram resultados próximos, sendo que a primeira, com célula de $5 \mathrm{~m}$, resultou em menor número de locais com quedas de água superiores a $2 \mathrm{~m}$, relativamente à segunda, com célula de $10 \mathrm{~m}$. Observou-se que, para a simulação SRTM-H250-M10, foi identificado apenas um local, distante $500 \mathrm{~m}$, aproximadamente, daquele levantado em campo, enquanto os demais locais identificados não existem em campo.

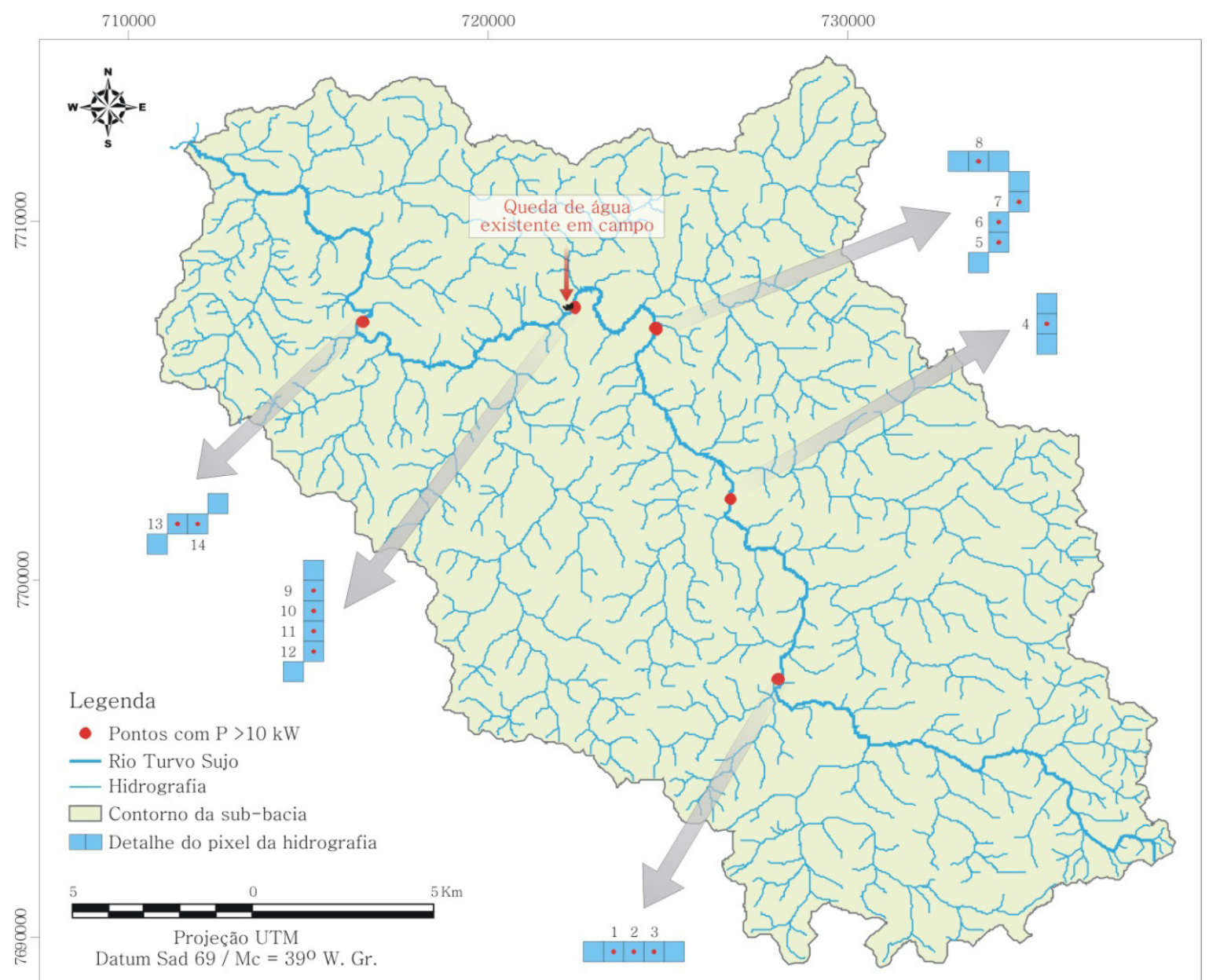

Figura 2. Quedas de água determinadas na simulação 4 (SRTM-H50-M10). 
Diante do exposto, constata-se uma discrepância entre os resultados obtidos neste trabalho e aqueles relatados por Scartazzini (1993). Neste, o autor objetivou a determinação automática das quedas de água ao longo dos cursos de água de uma bacia hidrográfica e as áreas de drenagem a montante delas. Seus resultados demonstraram grande coincidência entre os locais potenciais para geração de energia hidrelétrica obtidos com o SIG e os levantados em campo, utilizando-se dados de entrada na escala de 1:50.000, com curvas de nível equidistantes de $20 \mathrm{~m}$.

A metodologia utilizada, inicialmente, neste trabalho, é a mesma metodologia presente no estudo realizado por Scartazzini (1993). Entretanto, é importante ressaltar que, ao confrontar os dados obtidos nas simulações com aqueles existentes em campo, verificou-se uma enorme inconsistência. Assim, a metodologia foi modificada de forma a simular, com maior fidelidade, a realidade de campo. Para tanto, foram realizadas duas simulações, PTCM5 e PTCM10. Nelas utilizaram-se, como dados de entrada, os pontos cotados obtidos do levantamento topográfico, realizado nas imediações da queda de água identificada. Estes pontos foram associados às curvas de nível do IBGE na escala de 1:50.000.

Na Figura 3, é apresentado o resultado da primeira simulação, PTCM5. Observa-se que os resultados foram satisfatórios, pois, o local determinado com a metodologia foi idêntico ao trecho levantado em campo. Em princípio, este resultado era esperado, pois, nesta simulação foram utilizados os pontos cotados.

$\mathrm{Na}$ segunda simulação, PTCM10, foram identificados dois locais potenciais para geração de energia hidrelétrica, sendo somente um condizente com a realidade em campo. Neste sentido, é importante destacar que, para a simulação com célula de $10 \mathrm{~m}$, utilizando-se pontos cotados obtidos ao longo do levantamento, obteve-se resultado satisfatório, mas com identificação ilusória de um local potencial para geração de energia hidrelétrica, ao contrário da simulação PTCM5, em que se obtiveram resultados adequados.

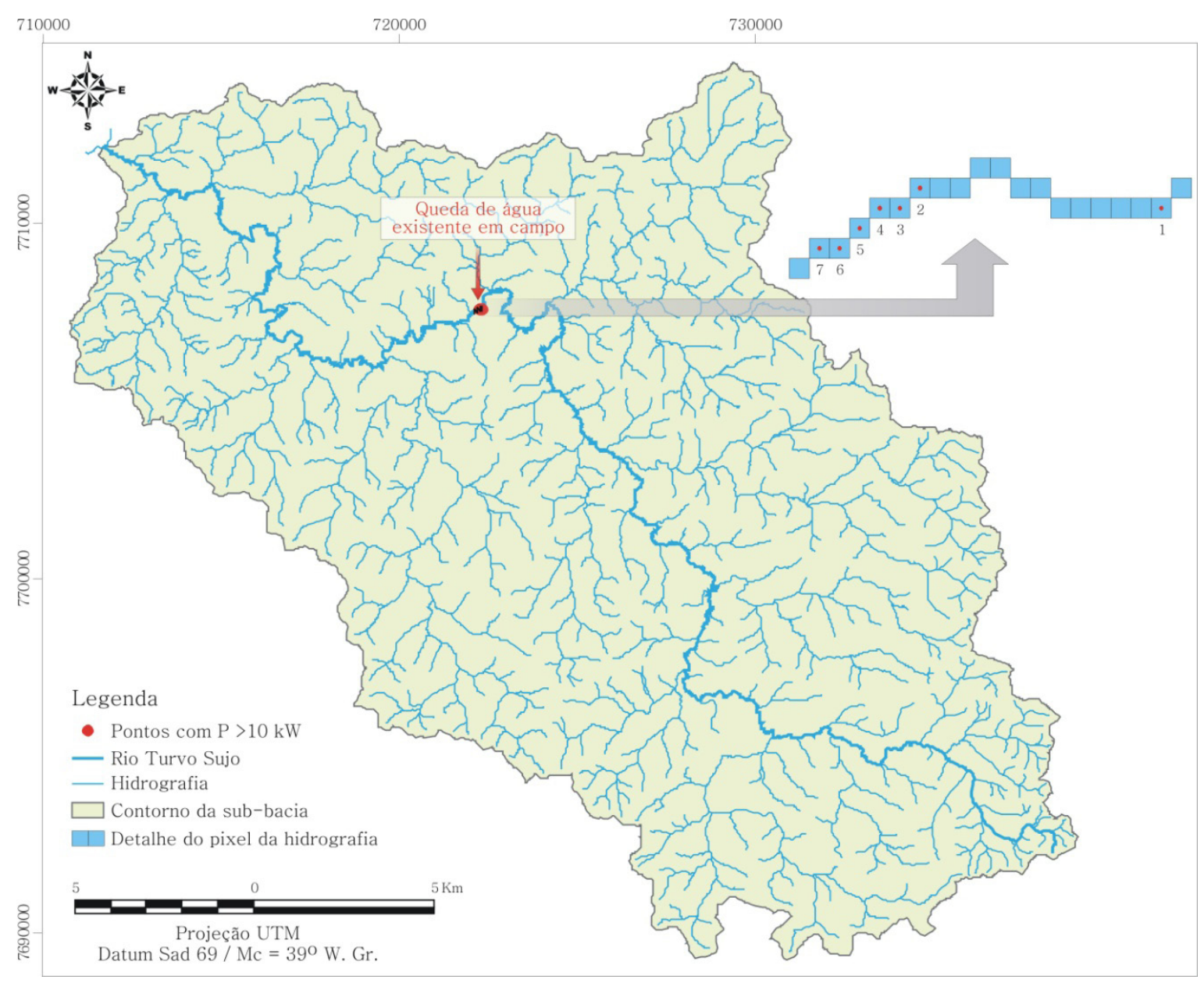

Figura 3. Queda de água determinada na simulação 7 (PTCM5). 
Em geral, comparando-se os resultados das demais simulações com os obtidos para resolução espacial das células de 5 e $10 \mathrm{~m}$, verificou-se que o tamanho da célula influencia fortemente a identificação de locais potenciais à geração de energia hidrelétrica, aumentando, ilusoriamente, o número de locais potenciais à medida que o tamanho da célula é aumentado. Estes resultados são explicados pelo fato de a interpolação ocorrer de forma diferente, de acordo com o tamanho da célula, ou seja, com célula de $5 \mathrm{~m}$, o modelo divide em maior número de fatias os valores das cotas. Por outro lado, com célula de $10 \mathrm{~m}$, observou-se um número maior de células na grade com valores próximos ou iguais e, em alguns trechos da hidrografia, a ocorrência de mudanças bruscas nos valores das cotas, resultando um aumento inconsistente dos locais, com presença de quedas de água.

Portanto, a presente metodologia mostrou-se eficaz para determinação de locais potenciais para geração de energia hidrelétrica, desde que se tenham dados de entrada (pontos cotados, curvas de nível ou SRTM) com nível de detalhamento suficiente para a determinação adequada das cotas. Verificou-se, também, que não é possível determinar quedas de água com valores entre 2 e $8 \mathrm{~m}$, utilizando-se as curvas de nível do IBGE, equidistantes de $20 \mathrm{~m}$, como dados de entrada, ou seja, os mesmos dados utilizados por Scartazzini (1993).

Para a simulação SRTM-H50-M10, o valor encontrado para as quedas foi em torno de $2,00 \mathrm{~m}$, com potência variando de 21,62 a $22,80 \mathrm{~kW}$, enquanto, na simulação PTCM5, as quedas de água variaram de 2,00 a 2,23 $\mathrm{m}$ e as potências, de 21,64 a 23,98 kW. Estes resultados evidenciam pequenas variações nos valores de quedas de água e de potência, para as duas simulações realizadas. No entanto, a simulação PTCM10 apresentou valores de quedas de água variando de 2,28 $\mathrm{m}$ a 2,91 m, resultando potências maiores que aquelas apresentadas nas simulações SRTM-H50-M10 e PTCM5. Vale aqui ressaltar que foram discutidos os resultado dessas simulações pelo fato de que com elas foram encontrados locais potenciais com localização próxima àquela determinada em campo.

Ressalta-se, ainda, que os valores de quedas de água, obtidos nas simulações, representam a diferença de nível entre o ponto indicado na hidrografia e um ponto localizado entre $40 \mathrm{~m}$ e 56,5 $\mathrm{m}$ a montante. Desta forma, apenas com os resultados apresentados, não é possível a determinação do potencial da queda de água total existente.

A validação dos resultados foi realizada pela individualização do trecho do rio Turvo Sujo, com extensão de aproximadamente $300 \mathrm{~m}$, onde foi constatada a única queda de água significativa existente na região em estudo.

Na Figura 4, estão plotados os perfis longitudinais do trecho analisado, para cada simulação realizada. Observa-se que a queda levantada em campo tem valor total aproximado de $8,80 \mathrm{~m}$ e uma extensão de $300 \mathrm{~m}$. A simulação que mais se aproximou do levantamento em campo foi a PTCM5, com uma queda total de $8,75 \mathrm{~m}$.

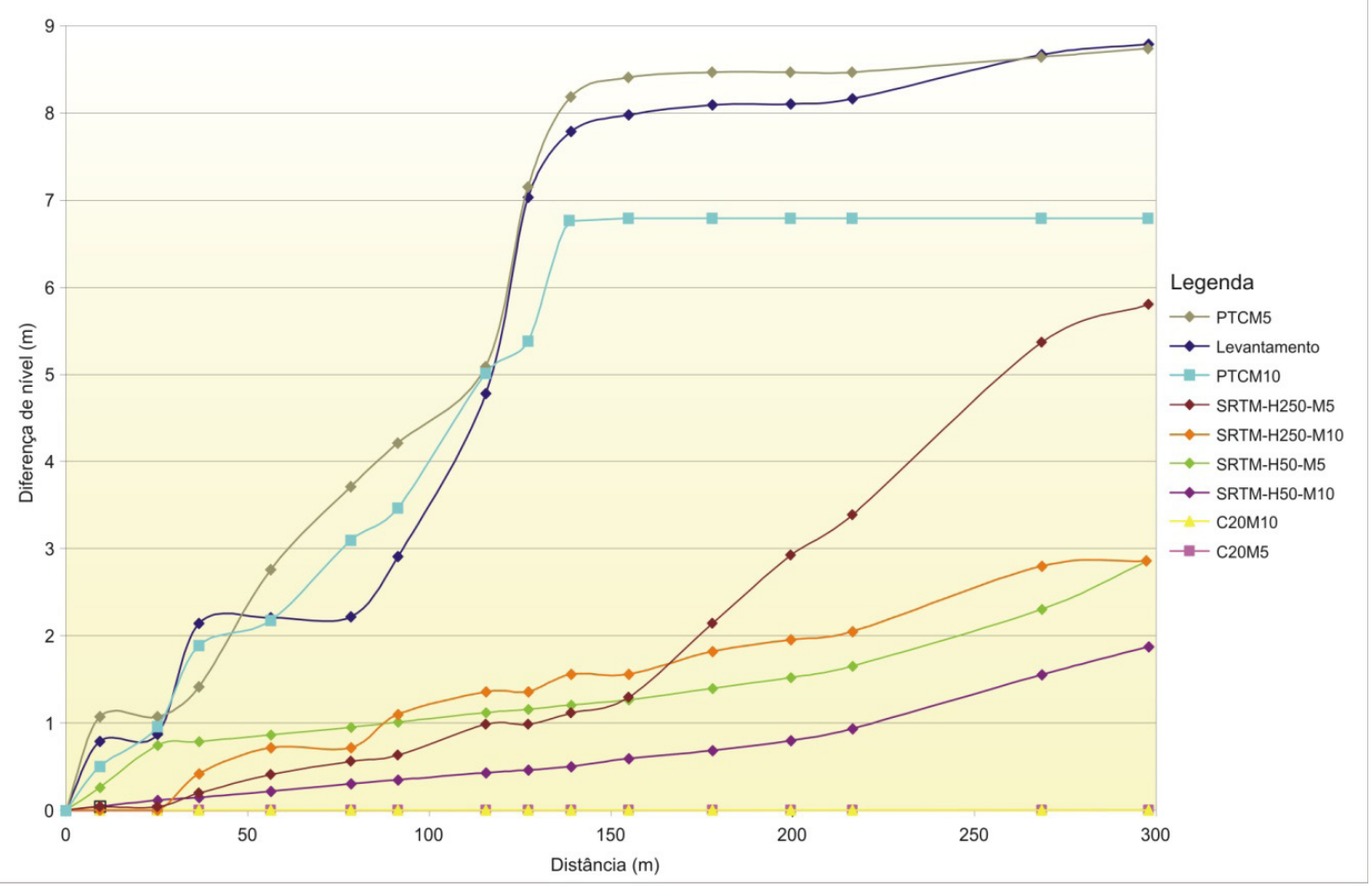

Figura 4. Quedas de água versus distância para o trecho analisado. 
Ao longo do trecho analisado, a maior variação entre a queda de água levantada em campo e a simulada com a metodologia na simulação PTCM5 foi de $1,60 \mathrm{~m}$, para a distância de $78 \mathrm{~m}$. Este resultado é animador no que se refere à utilização da metodologia com vistas à identificação de aproveitamento hidrelétrico. Parece evidente que, se a metodologia fosse aplicada numa sub-bacia de relevo mais acidentado ao longo do curso de água, as possíveis quedas de água seriam prontamente identificadas.

A simulação PTCM10 apresentou uma tendência de acréscimo em altitude similar à simulação PTCM5 (exceto no formato das curvas), mas, permanecendo praticamente constante a partir da distância de 140 $\mathrm{m}$, bem como indicou uma diferença de quase 1,95 m para a queda levantada em campo no trecho. As simulações que utilizaram os MDE's do SRTM não representaram bem a realidade encontrada em campo, pois, demonstraram um crescimento no perfil longitudinal muito abaixo do real. Destas, somente a simulação SRTM-H250-M5, a partir dos $150 \mathrm{~m}$, apresentou declividade bem acentuada, atingindo uma diferença de queda total de aproximadamente $3 \mathrm{~m}$, em relação àquela levantada em campo. Também, na Figura 4, observa-se que somente as curvas de nível disponibilizadas pelo IBGE (C20M5 e C20M10), com equidistância de $20 \mathrm{~m}$, não apresentam um detalhamento do relevo que possibilite a determinação das quedas de água existentes no trecho analisado. Este fato pode ser atribuído ao valor da queda de água total ser de $8,80 \mathrm{~m}$, ou seja, tem valor menor que a equidistância das curvas de nível utilizadas.

Utilizando-se os valores de quedas de água total, determinados com o levantamento de campo e aqueles obtidos na simulação PTCM5, para o trecho analisado, seria possível gerar potência de aproximadamente $94,75 \mathrm{~kW}$. Desta forma, caso fosse utilizada a queda total existente, a simulação com a metodologia teria apresentado, praticamente, o mesmo resultado.

Analisando os resultados, é possível constatar que, quanto menor for a queda de água a ser identificada, maior é a dificuldade em gerar um modelo que a represente. Por outro lado, verifica-se que a utilização de dados de entrada com maiores detalhamentos permitem a utilização da metodologia proposta, neste trabalho, com aproximação aceitável em nível de planejamento inicial dos recursos hidráulicos existentes em uma bacia. Uma tecnologia promissora para obtenção de um modelo do terreno mais detalhado é o sensor Lidar, que permite a obtenção de informações de altimetria com até 0,15 $m$ de equidistância.

\section{CONCLUSÕES}

- Os locais identificados nas simulações como potenciais para a geração de energia hidrelétrica, tanto com os dados de entrada obtidos das cartas topográficas do IBGE, quanto com os obtidos do SRTM, não apresentam resultados satisfatórios para a região em estudo. Porém, quando os dados do IBGE são utilizados em conjunto com os dados levantados em campo, os resultados são satisfatórios;

- Os resultados da simulação PTCM5 (pontos cotados obtidos ao longo do levantamento topográfico, mais as curvas de nível do IBGE no restante da sub-bacia, hidrografia na escala de 1:50.000 e resolução espacial de $5 \mathrm{~m}$ ) mostraramse eficazes na identificação de seções com potencial para a geração de energia elétrica; e

- Na simulação, empregando PTCM10 (pontos cotados obtidos ao longo do levantamento topográfico, mais as curvas de nível do IBGE no restante da sub-bacia, hidrografia na escala de 1:50.000 e resolução espacial de $10 \mathrm{~m}$ ) fica evidente a influência da resolução espacial, da célula do MDEHC utilizado, na determinação de locais com potenciais para geração de energia elétrica.

\section{REFERÊNCIAS BIBLIOGRÁFICAS}

ANEEL - Agência Nacional de Energia Elétrica. Disponível em: <www.aneel.gov.br>. Acesso em: 19 mar. 2006.

\section{EUCLYDES, H.P. (org.). Atlas Digital das Águas de Minas. Viçosa: CPT, 2005.}

CARVALHO, G.S.; REIS, R.S.; FREIRE, C.C. Reavaliação do potencial hidro-energético da bacia hidrográfica do rio Mundau. In: VII Simpósio de Recursos Hídricos do Nordeste. Anais... São Luiz, MA, 2004. 20 p. 
CCPE - Comitê Coordenador de Planejamento da Expansão dos Sistemas Elétricos. Plano Decenal de Expansão do Setor Elétrico Brasileiro 2001/2010. Brasília, DF, Ministério de Minas e Energia, 2002. 290p.

DAS, S.; PAUL, P.K. Selection of Site for Small Hydel Using GIS in the Himalayan Region of India. Journal of Spatial Hydrology. North Lauderdale USA. v.6, n.1, p.18-28, 2006.

ELETROBRÁS. Manual de Micro-centrais Hidrelétricas. Brasília, DF, MME, 1985.

HUTCHINSON, M.F. A locally adaptive approach to the interpolation of digital elevation. Disponível em: <wwwl.gsi.go.jp/ geowww/globalmap-gsi/gtopo30/papers/local. html>. Acesso em: 05 fev. 2007.

IBGE - Instituto Brasileiro de Geografia e Estatística. Cartas topográficas do mapeamento sistemático: Ervália, São Miguel do Anta, Teixeiras, Viçosa e Ponte Nova, escala varia, Projeção Universal Transversa de Mercator, M.C. $=\mathbf{4 5}^{\circ}$ W. Gr. Disponível em: <www.ibge.gov.br>. Acesso em: 15 jan. 2006.

MAUAD, F.F.; OLIVEIRA. H.R.; CORRÊA FILHO, C.R.R.; MARIOTONI, C.A. O papel das pequenas centrais hidrelétricas frente à reestruturação do setor elétrico brasileiro. In: XV Simpósio Brasileiro de Recursos Hídricos. Anais... Curitiba, PR, 2003. 20p.

MME - Ministério de Minas e Energia.
Disponível em: <www.mme.gov.br>. Acesso em: 19 set. 2006.

NEVES, M.M.; SILVA, L.S.; CANTARINO, A.D.; CAMPAGNOLI, F. Expansão da rede hidrometeorológica: a visão dos pequenos produtores hidrelétricos. In: III Simpósio de Recursos Hídricos do Centro-Oeste. Anais... Goiânia, GO, 2004. 20p.

PREFEITO, L. F. B.; MAUAD, F. F. O atual modelo do setor elétrico brasileiro.In: III Simpósio de Recursos Hídricos do CentroOeste, Goiânia, GO, 2004. 20p.

RIBEIRO, C.A.A. S.; CHAVES, M.A.; SOARES, V. P.; EUCLYDES, H. P. Modelos digitais de elevação hidrograficamente consistentes para a Amazônia Legal. In: $2^{\circ}$ Simpósio de Recursos Hídricos do Centro-Oeste. Anais... Campo Grande, MS, 2002. 20p.

SCARTAZZINI, L.S. Estudo do potencial hidro-energético na bacia hidrográfica do rio Pardinho-RS, para viabilizar instalações hidroelétricas de pequeno porte atendendo residências rurais isoladas. 1993. 95f. Dissertação (Mestrado em Engenharia Civil) -, Universidade Federal do Rio Grande do Sul, Porto Alegre, RS, 1993.

SUGAI, M.R.V.B., A expansão da oferta de energia elétrica com a preservação dos usos múltiplos dos recursos hídricos. In: XV Simpósio Brasileiro de Recursos Hídricos. Anais... Curitiba, PR, 2003. 20p. 